\title{
Peningkatan Kualitas Ruang dan Infrastruktur pada Perbatasan Surabaya Barat
}

\author{
Joshua Gama Wastara dan Defry Agatha Ardianta \\ Departemen Arsitektur, Fakultas Arsitektur, Desain dan Perencanaan, Institut Teknologi Sepuluh Nopember (ITS) \\ e-mail: agathadefry@arch.its.ac.id
}

\begin{abstract}
Abstrak-Sebagai kota besar bukan berarti setiap wilayah Surabaya harus menjadi kawasan wisata dan destinasi. Setiap wilayah kota memiliki fungsinya masing masing. Namun tidak memiliki fungsi wisata bukan berarti infrastruktur suatu wilayah tidak perlu diperhatikan. Wilayah perbatasan Surabaya barat (benowo) tidak memiliki area wisata yang menarik, sampai pertengahan 2017 tidak memiliki taman satupun, infrastruktur kota kurang dan akses jalan sangan minim, dan menjadi wilayah yang tidak dikenal sebagai apapun selain tempat pembuangan sampah akhir. Tujuan akhir pada desain berfokus pada arsitektur yang meningkatkan infrastruktur wilayah benowo perbatasan kota Surabaya dan Kabupaten Gresik. Namun arsitektur tetap mengintegrasikan hubungan bangunan, ruang terbuka hijau dan kebutuhan masyarakat sekitar. Privasi dalam desain ini menjadi poin yang sangat penting karena pertemuan antara penghuni dan pengunjung tiap hari akan mempengaruhi personal space masing - masing orang. Programatik fasilitas dan ruang harus menjadi sangat fleksibel untuk memberikan kenyamanan bagi masyarakat sekitar juga.
\end{abstract}

Kata Kunci-Surabaya, Perbatasan, Humanis, Privasi, Fasilitas, Infrastruktur.

\section{PENDAHULUAN}

$\mathrm{M}$ ENURUT buku Monograf Hiperealitas Pencitraan Politik Risma: Persepsi Masyarakat atas pekerjaan Risma sebagai walikota Surabaya 2010-2015, Walikota Surabaya, Tri Risma Harini atau yang akrab dipanggil Bu Risma, memperlihatkan dengan jelas bahwa beliau ingin membawa Surabaya kepada kota yang menghadirkan keseimbangan ruang terbuka dengan bangunan agar memberi kenyamanan bagi manusianya. Surabaya merupakan kota metropolitan yang memperhatikan Public space sebagai salah satu kepentingan untuk masyarakat. Perhatian terhadap ruang terbuka ini juga didukung oleh misi kota Surabaya pada poin ke 4 dan ke 5 [1]. Tri Risma juga mengusahakan kesetaraan dalam ifrastruktur seluruh daerah Surabaya, serta kondisi kenyamanan masyarakat yang setara di semua wilayah di Surabaya. Beberapa cara yang dilakukan untuk memanusiakan manusia di Surabaya adalah menyediakan lingkungan yang nyaman dalam hal panas, kebersihan dan kelayakan bagi semua masyarakat [2].

Wilayah Surabaya Barat, Perbatasan Kota Gresik, Jalan Benowo, kecamatan Pakal tidak memiliki infrastruktur yang sebaik wilayah Surabaya lainnya (Gambar 1). Tidak menggambarkan Identitas kota Pahlawan juga (hampir tidak ada situs sejarah heroik di wilayah ini) dan belum menggambarkan Identitas kota Taman maupun wilayah hijau. Sejak 2011 - 2018 pinggiran surabaya barat masih belum banyak terjamah oleh perkembangan pembangunan

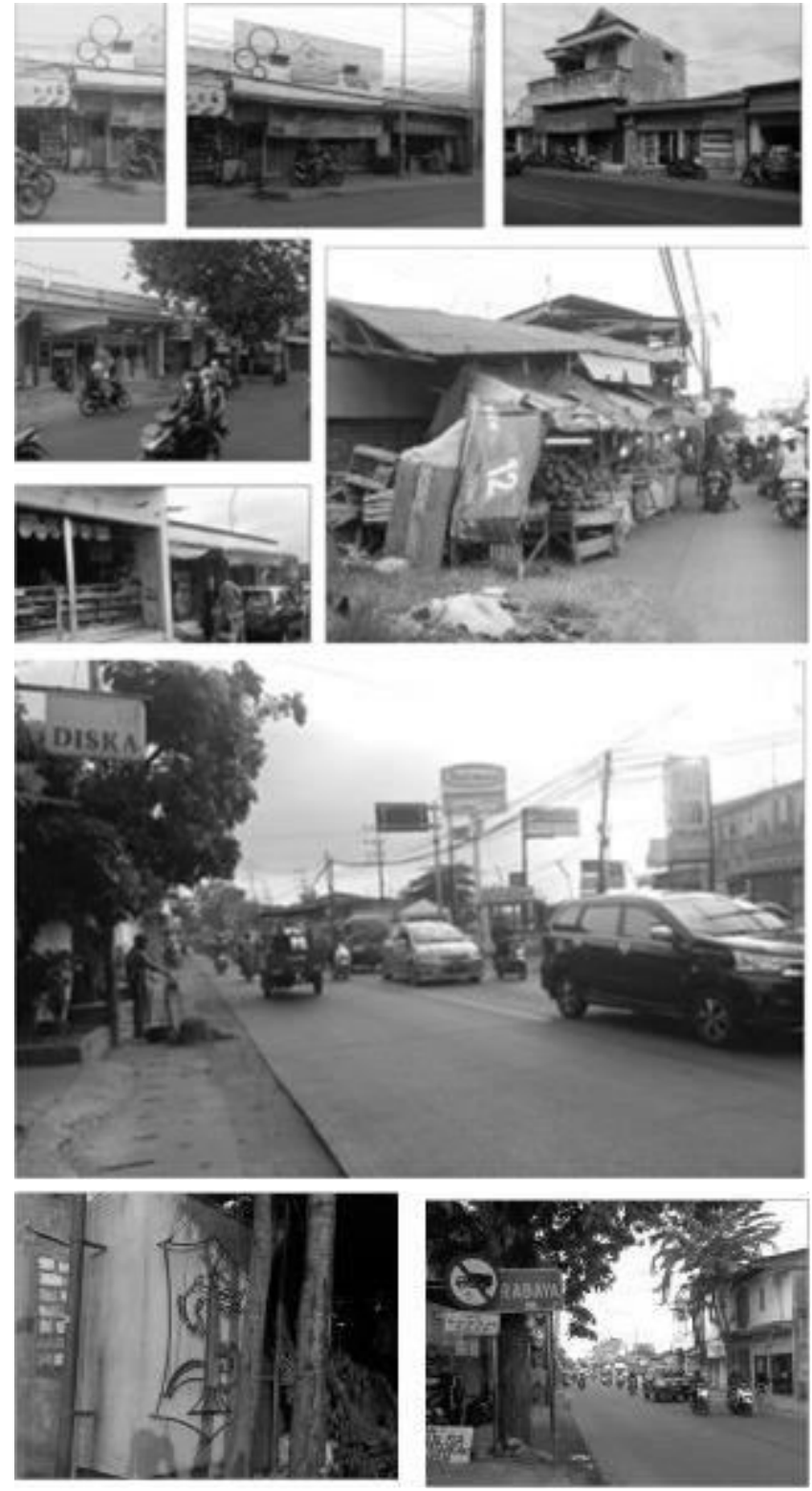

Gambar 1. Kondisi area Perbatasan Benowo dan Gresik.

pemerintah. Namun, wilayah ini memiliki potensi karena merupakan salah satu titik masuk dari arah kabupaten Gresik [3].

Tujuan desain adalah arsitektur yang dapat mengintegrasikan bangunan dan ruang terbuka hijau dengan aktivitas masyarakat agar dapat memberikan kualitas yang lebih baik dari sebuah lansekap. Langkah yang dituju pertama adalah infrastruktur yang melayani kebutuhan manusia senyaman mungkin. Kedua adalaha keseimbangan urgensi 


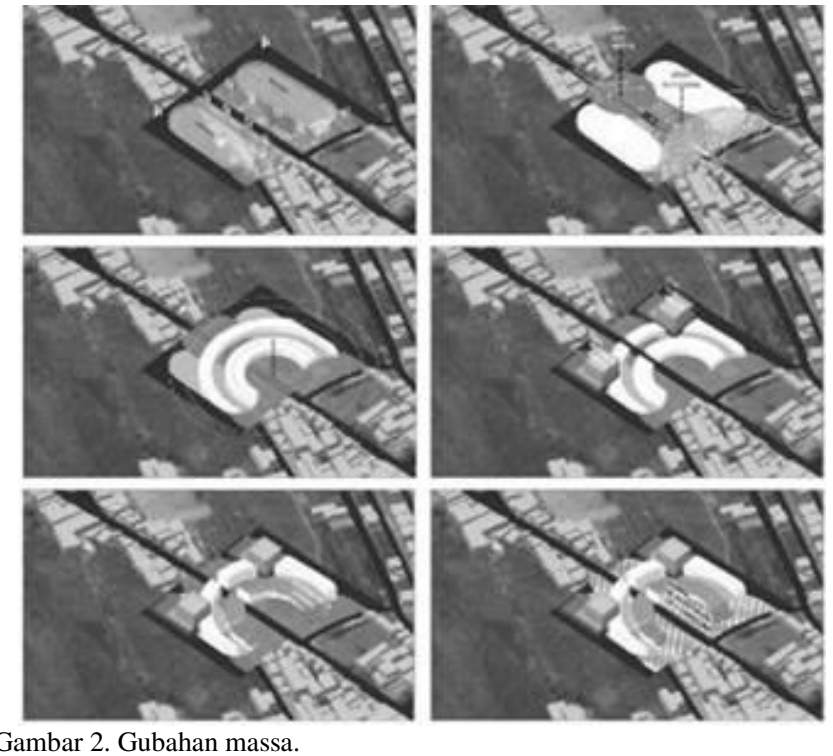

Gambar 2. Gubahan massa.

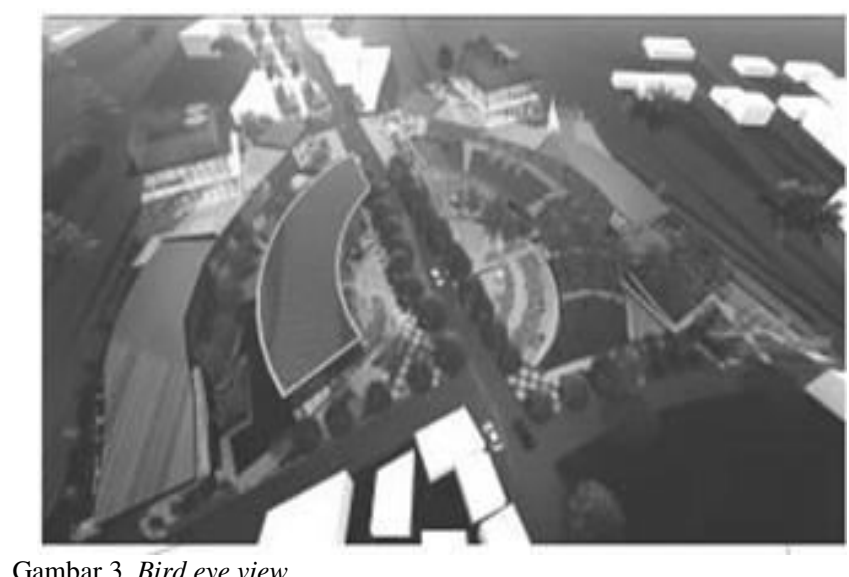

Gambar 3. Bird eye view.

ruang terbuka dan bangunan. Ketiga, fokus kepada kualitas ruang dan aksesibilitas.

Permasalahan berikutnya yang akan diangkat adalah bagaimanakah upaya membuat infrastruktur publik yang mampu meningkatkan kualitas sosial, lingkungan masyarakat dan sebagai finacial generator untuk meningkatkan kenyamanan dan finansial masyarakat sekitar.

\section{METODA PERANCANGAN}

Tujuan desain awal mengarahkan respon dimana arsitektur harus memperhatikan manusia sebagai perhatian utama dalam isu Humanis ini. Pendekatan kota Surabaya adalah menyeimbangkan ruang terbuka hijau dengan bangunan, dan menyetarakan infrastruktur pada semua area. Melalui kedua hal tersebut maka Socio-Enviromental Approach merupakan pendekatan yang tepat dalam arsitektur merespon isu tersebut, dimana pendekatan ini mencermati aspek manusia dan juga lingkungan di wilayah tersebut [4].

Metode desain diperlukan untuk menjawab masalah yang ada dan sebagai alat untuk membantu cara pandang / pendekatan desain agar lebih tajam dalam menganalisa. Pertama, metode desain Precedent : Transforming of Spesific
Tabel 1.

Tabel Pemrograman dari Tingkat Keramaian Pengguna

\begin{tabular}{|c|c|c|c|}
\hline & OPTIMAL RENDAH & BISA DI TINGGI DAN RENGMH & OPTIMAL TINGG| \\
\hline \multirow{6}{*}{ ATTRACTIVE FACIUTY } & RUANG PENULALAN & WAHANAA BERIMAIN & PLATA/ HAROSCAPE \\
\hline & MEETING AREA & AREA BEROLAHRRGAA & \\
\hline & ASEA BERUSTRRAMAT & TRACK TAMAN & \\
\hline & JOGGING TRACK & AREASENAM & \\
\hline & TAMANAR & SPOTCAFE & \\
\hline & & POCOCOURT & \\
\hline \multirow{4}{*}{$\begin{array}{c}\text { CAN QE ATTRACTIVE } \\
\text { FACILTY }\end{array}$} & PARKIRUMUM & RUANGTMKAN & RUANGCUCIEMUN \\
\hline & GARASI & ELEMENAR & RUANG TARU \\
\hline & & R. ISTIRAHAT TOLO & AREA BERSANTAI \\
\hline & & TAMMAN BACA & RUANG TERAS \\
\hline \multirow{7}{*}{ DEVOTEO FACILTY } & RUMNG ADMUNISTRASI & ALANG KERAA & A. KELUARGA \\
\hline & RUANG PENYMMPANAN & TOLETTUMUM & DAPUR \\
\hline & PUSATINFORMUSI & Pasinga & KAMGR TIOUR \\
\hline & TEMPATIBADAH & STANOSNAACK & R. SAMAR MANDI \\
\hline & POS KESEHATAN & VEG:TASI & GUDANG RUMAH \\
\hline & KANTOR PENGOLAHAN & & \\
\hline & PARK R SEPED PANCAL & & \\
\hline
\end{tabular}

Fasilitas Publik

Fasilitas Semi Publik

Fasilitas Privat

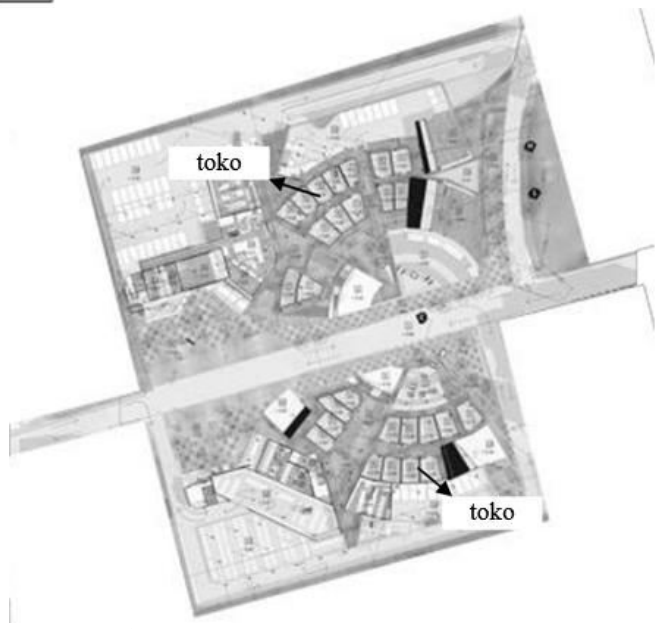

Gambar 4. Layout plan.

Model digunakan untuk menjawab bagaimana arsitektur memunculkan identitas, bagaimana mewujudkan keseimbangan antara ruang terbuka dan bangunan, serta pendekatan dan kemungkinan lainnya yang belum diketahui, melalui studi dari karya / desain yang sudah pernah dilakukan. Kedua, metode desain Responses to site : Contextualism digunakan untuk mendukung pendekatan SocioEnvironmental dimana salah satu aspek yang paling diperhatikan adalah lingkungan daerah sekitar [5].

Metode ini terjadi pada setiap proses desain yang dilakukan karena metode ini merupakan dasar utama dari analisa pada seluruh kondisi lahan. Fungsi yang digabungkan dengan konteks lahan untuk menyelesaikan permasalahan desain akan menemui beberapa masalah. Metode dengan memperhatikan dan menganalisa konteks lahan membantu menentukan masalah yang diperhatikan untuk diselesaikan.

\section{HASIL DAN EKSPLORASI}

\section{Konsep Bentuk}

Sesuai dengan metode yang digunakan, contextualism method. Bentuk bangunan terkonsep melalui kebutuhan kebutuhan ruang dari area sekitar (Gambar 2). Berhubung 
Tabel 2.

Tabel Pemrograman Fasilitas dari Privasi Pengguna

\begin{tabular}{|c|c|c|c|}
\hline & HARLS DOALAM & EISA CI WUAR & HaRUS QT LUAR: \\
\hline \multirow{6}{*}{ PRIVATE } & PILWGSERVS / AOMIINSTRASI & FLUNG KELLLARCA & \multirow{6}{*}{. } \\
\hline & FLLANG PERUYIMPAIAAN & RUANSMMKAN & \\
\hline & GLGAPGG RLESAH & BLANGG IS IILAHAT IOKO & \\
\hline & CAPUR & & \\
\hline & KAML3 TnLLA & & \\
\hline & RUAANG KERUA & & \\
\hline \multirow{5}{*}{ SEM Fivarte } & RUANG KAMAR ISANDI & RUANG EUCI JELU? & \multirow{5}{*}{. } \\
\hline & TOLCT UMLM & OCMENAIR & \\
\hline & KANTOR PENGOLAFUR & RuAsctasu & \\
\hline & & PDSIAGA & \\
\hline & & PUSATINEORMAS & \\
\hline \multirow{11}{*}{ PLeLic } & PCS KESOLGTARA & MROA BLRSANTM & MEETHEGAPEA \\
\hline & TEMPAT IBACAH & STANDSHACK & AREASENAM \\
\hline & & WAHANG BERMAIN & DOGGNG TRACK \\
\hline & & AABA BEAOCAR RAGS & PLAZA / HAROSCAPE: \\
\hline & & PARKIR/GoRASI & VECETASI/SCFTSCAPE \\
\hline & & PAPS R KENDAFAASN PBIPADI & O. TRACK TALAS \\
\hline & & RLLANG PERULGLAN & FLEMENAR \\
\hline & & 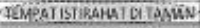 & A RLARG TEAS RLRLAH \\
\hline & & nUENG TANUN EACA & PASBIR SEDEDA PANCAL \\
\hline & & FCOD COLIRT & TAMANA AIR \\
\hline & & SPUTCAFE & \\
\hline & \multicolumn{3}{|c|}{ Atrractive : Fasilitas yang menarik perhatian } \\
\hline & \multicolumn{3}{|c|}{$\begin{array}{l}\text { Devoted : (Dikhususkan) Fasilitas yang } \\
\text { didatangi untuk melakukan kegiatan tertentu }\end{array}$} \\
\hline & \multicolumn{3}{|c|}{ 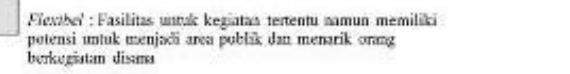 } \\
\hline
\end{tabular}

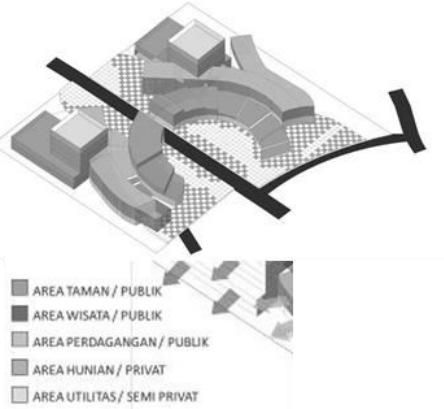

Gambar 5. Plotting fasilitas pada massa.

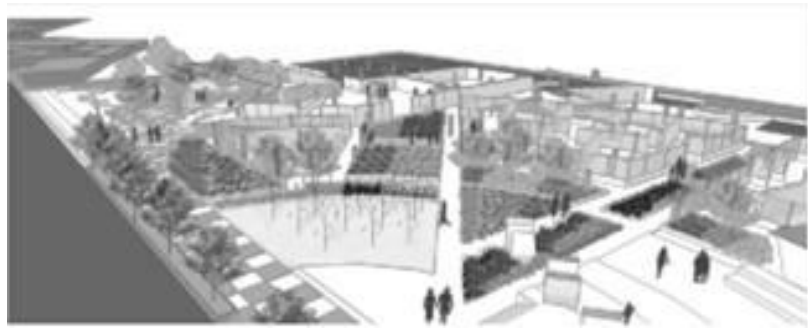

Gambar 6. Vegetasi, material, taman, dan taman air.

desain adalah ruang publik taman dan wisata maka langkah pertama adalah meletakkan area yang digunakan sebagai "area interaksi" dan "area teknis" seperti parkiran. Desain menghadirkan semua area interaksi di depan berdekatan dengan arah yang paling mudah dijangkau pejalan kaki. Berikutnya memasukkan massa lindungan untuk fasilitas yang perlu terlindungi, agar urgenitas antara ruang terbuka dan tertutup bisa seimbang. Area - area yang dibuka, diberikan naungan dan lindungan ditentukan dari lingkungan yang ada di dekatnya dan potensi arah gerak manusia kedalam lahan.

2. Permasalahan Banyak Kebutuhan Fasilitas

Pendekatan pemerintah kota Surabaya kepada masyarakatnya adalah tidak menggusur dan sekedar mengganti rugi, melainkan merelokasi. Pendekatan tersebut

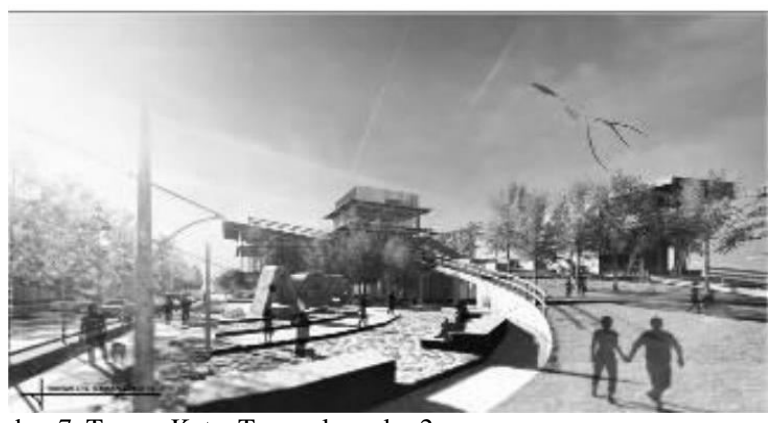

Gambar 7. Taman Kota, Taman layer ke-2.

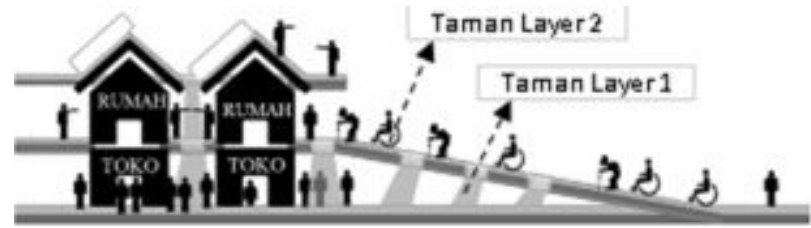

Gambar 8. Konsep taman 2 layer.

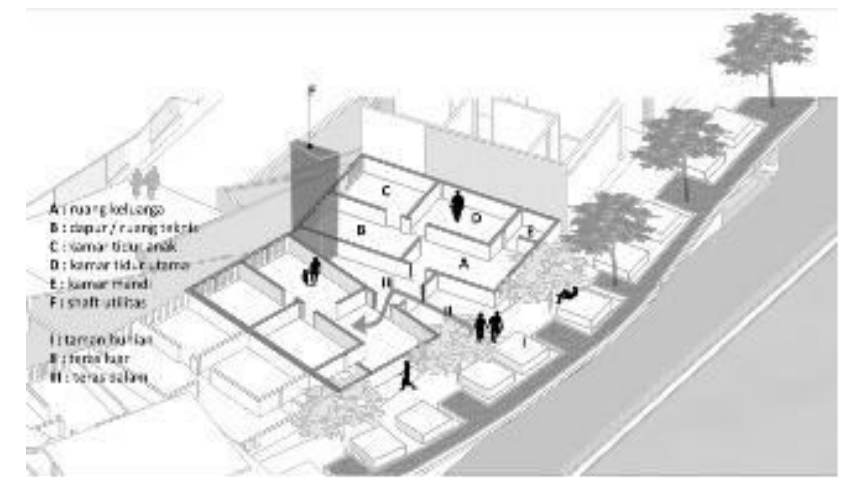

Gambar 9. Bentuk keterhubungan antar hunian.

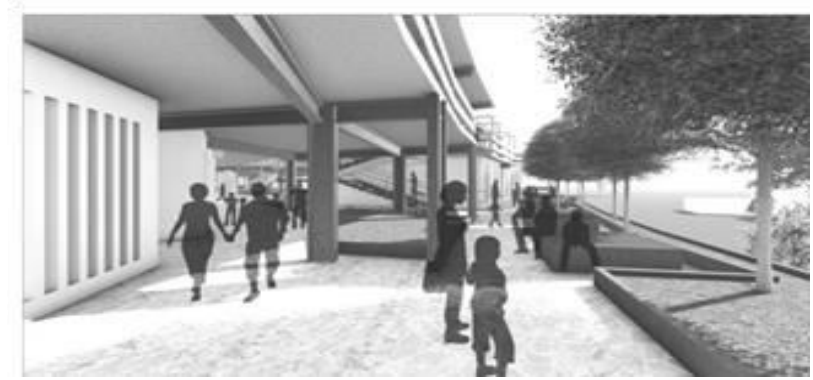

Gambar 10. Suasana area hunian.

menggerakkan pemilihan fungsi bangunan juga memperhatikan hunian warga yang ada di kawasan tersebut [3]. Obyek arsitektur yang digunakan pada Desain adalah penggabungan 3 fungsi. Fungsi tersebut adalah fungsi hunian dengan rumah tinggal, fungsi perdagangan dengan toko, dan fungsi fasilitas kota dengan taman kota dan fasilitas wisata untuk membantu meningkatkan kualitas ruang dan finansial area sekitar. Ketiga fungsi bangunan tersebut juga mempunya fasilitas masing masing yang membuat kebutuhan ruang yang banyak.

Berdasarkan fungsi yang dihadirkan, desain memiliki keharusan untuk memfasilitasi banyak fasilitas dalam lahan yang terbatas. Keterbatasan ini mengarahkan penataan tiap fasilitas tidak lagi terpaku harus berkumpul dengan fasilitas sesama fungsinya saja, melainkan ditata berdasarkan 


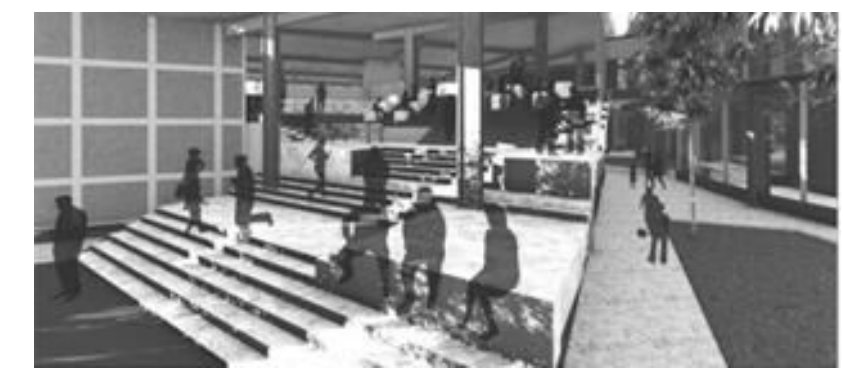

Gambar 11. Sharing activity, ruang tamu bersama.

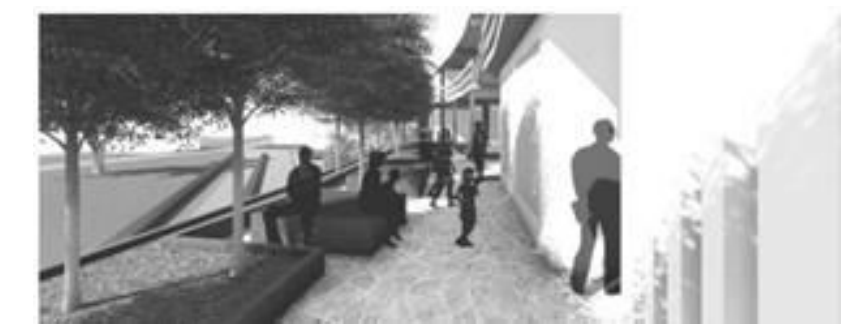

Gambar 12. Sharing Activity, taman dan teras bersama.

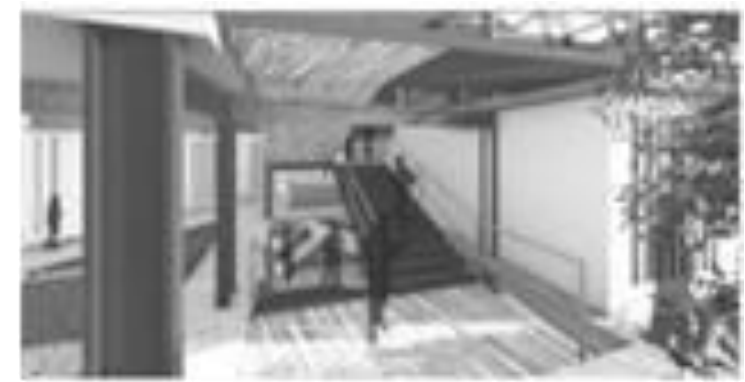

Gambar 13. Sharing Activity, tangga utama bersama.

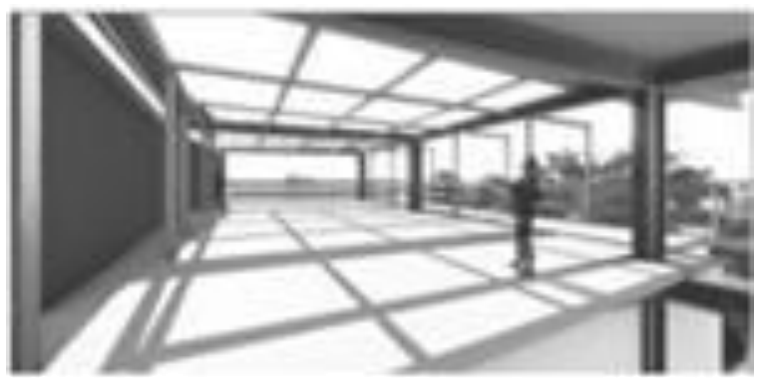

Gambar 14. Sharing Activity, ruang jemur bersama.

kemampuan fasilitas tersebut menarik aktivitas manusia. Selain itu, terbatasnya lahan memungkinkan untuk fasilitas diletakkan pada level yang berbeda.

3. Konsep Pemrograman Fasilitas

Fasilitas dibagi berdasarkan tingkat keintiman aktivitas tersebut dengan penggunaan. Ruang tidak dikumpulkan berdasarkan kesamaan tipe bangunan saja. Sehingga, fungsi tiap fasilitas dapat setara dan aktivitas pada hunian tidak terganggu dengan aktivitas taman wisata, begitu pula sebaliknya (Tabel 1). Fasilitas dibagi berdasarkan potensi letaknya untuk menciptakan kualitas antar ruang baru pada tiap lantainya. Hal ini untuk mengatasi kebutuhan fasilitas lebih banyak dibanding luasan lahan yang terbatas (Tabel 2).

\section{Permasalahan Target Desain}

Desain harus menghadirkan 3 fungsi yang berbeda dimana harus dapat diterima berbagai kalangan. Hunian untuk menengah kebawah, namun ada juga yang menengah dan

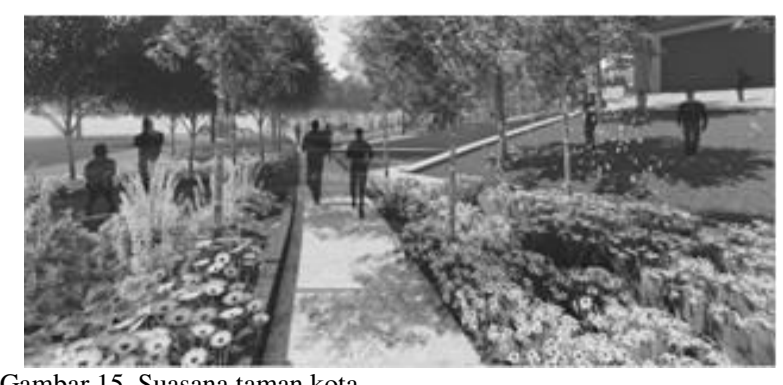

Gambar 15. Suasana taman kota.

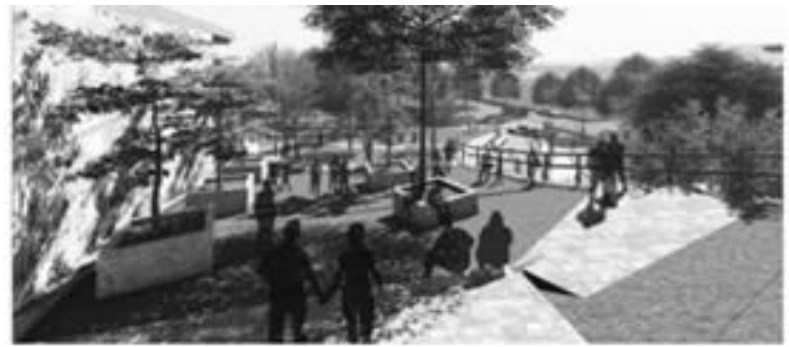

Gambar 16. Taman layer ke 2.

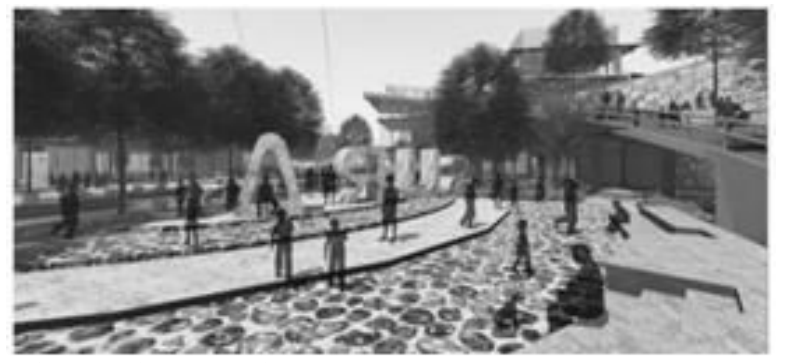

Gambar 17. Plaza taman kota.

menengah keatas. Taman Wisata memprioritaskan pengunjung, harus dapat menarik bagi kalangan atas dan diterima untuk kalangan menengah maupun menengah ke bawah.

5. Konsep Penggabungan Aktivitas

Fungsi yang dihadirkan pada desain merupakan gabungan dari 3 fungsi utama. Masing - masing fungsi memiliki fasilitas yang bisa dinikmati oleh publik secara bebas, dan beberapa fasilitas membutuhkan privasi penggunanya untuk dilindungi. Namun, ada perbedaan jumlah fasilitas yang publik maupun yang privat. Fungsi taman dan wisata memiliki fasilitas publik yang jauh lebih banyak dibandingkan fungsi hunian dan perdagangan. Hal tersebut membuat privasi satu fungsi dengan yang lainnya akan bertabrakan dan saling mengganggu.

6. Konsep Taman 2 Layer

Konsep taman 2 layer menciptakan kualitas ruang yang baru dari hunian, perdagangan dan taman berdasarkan pada permasalahan dari tipe bangunan. Jika ruang terbuka hijau selama ini hanya dianggap sebagai bagian lantai 1 dari bangunan, maka bagaimana jika taman tersebut dibuat menjadi 2 layer, menaikkan taman menjadi 2 tingkat (Gambar 8). Menyediakan taman bagi toko maupun rumah tinggal. Memenuhi kebutuhan interaksi warga rumah tinggal melalui taman di layer atas dan wisata pada taman layer bawah (Gambar 6 dan 7).

7. Konsep Hunian

Hunian adalah salah satu pendekatan Surabaya yang digunakan pada desain. Fungsi hunian merupakan relokasi dari 


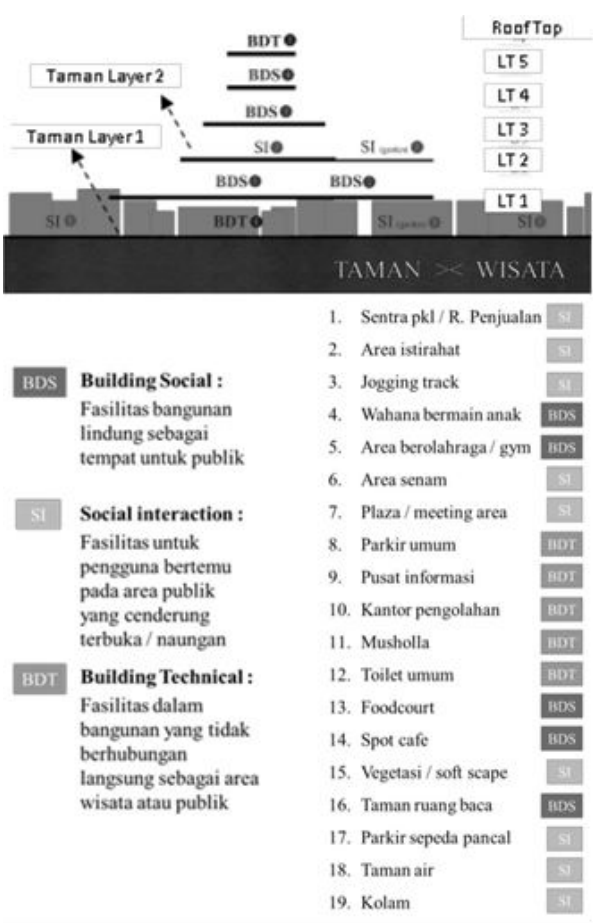

Gambar 18. Diagram penempatan fasilitas taman dan wisata.

fungsi eksisting lahan yang diambil, yaitu ruko atau lebih dikenal rumah dan toko. Hak kepemilikkan hunian dan seluruh fungsi pada desain adalah milik pemerintah. Dengan kata lain, hunian ini adalah hunian yang disewakan atau dikontrakkan. Penghuni bisa siapa saja penghuni sebelumnya maupun yang ingin menyewa (Gambar 10). Desain membentuk tatanan masa pada hunian agar akses penhuni tidak terganggu oleh aktivitas publik dan begitu pula sebaliknya. Luasan hunian eksisting sebelumnya berbeda beda. kenyamanan pada penghuni maka luasan minimal desain hunian disesuaikan dengan nilai terluas dari hunian eksisting sebelumnya (Gambar 9).

\section{Konsep Perdagangan}

Perdagangan juga merupakan relokasi dari fungsi eksisting lahan yang diambil. Perbedaannya stan toko atau perdagangan dikhususkan untuk penghuni toko eksisting, dan ada beberapa yang bisa disewakan. Desain menyediakan generator finansial baru bagi masyarakat dengan kulaitas ruang yang lebih baik. Bentukkan massa toko mengikuti massa utama yaitu berfokus dan mengarah pada 1 titik / center (Gambar 4 dan 6).

\section{Konsep Sharing Activity}

Keterbatasan lahan membuat adanya penyesuaian pada peletakan fasilitas. Hal ini dilakukan pada fungsi hunian, tujuannya adalah untuk memberikan ruang lebih dan membuat kualitas hunian yang baru (Gambar 8). Aktivitas pada hunian hampir $80 \%$ adalah aktivitas privat, hanya sedikit yang baik untuk bisa dipakai secara publik. Berdasarkan pembagian aktivitas dengan beberapa parameter (Tabel 1 dan 2), terdapat beberapa aktivitas semi privat dan semi publik hunian yang dapat ditarik keluar dari fungsi hunian, disesuaikan dan dijadikan publik.

Pertama adalah fasilitas taman dan teras atau ruang terbuka milik rumah. Hunian menengah keatas pada umumnya memiliki teras masing - masing yang dibatasi sendiri. Hunian menengah kebawah sering tidak memiliki ruang terbuka hijau
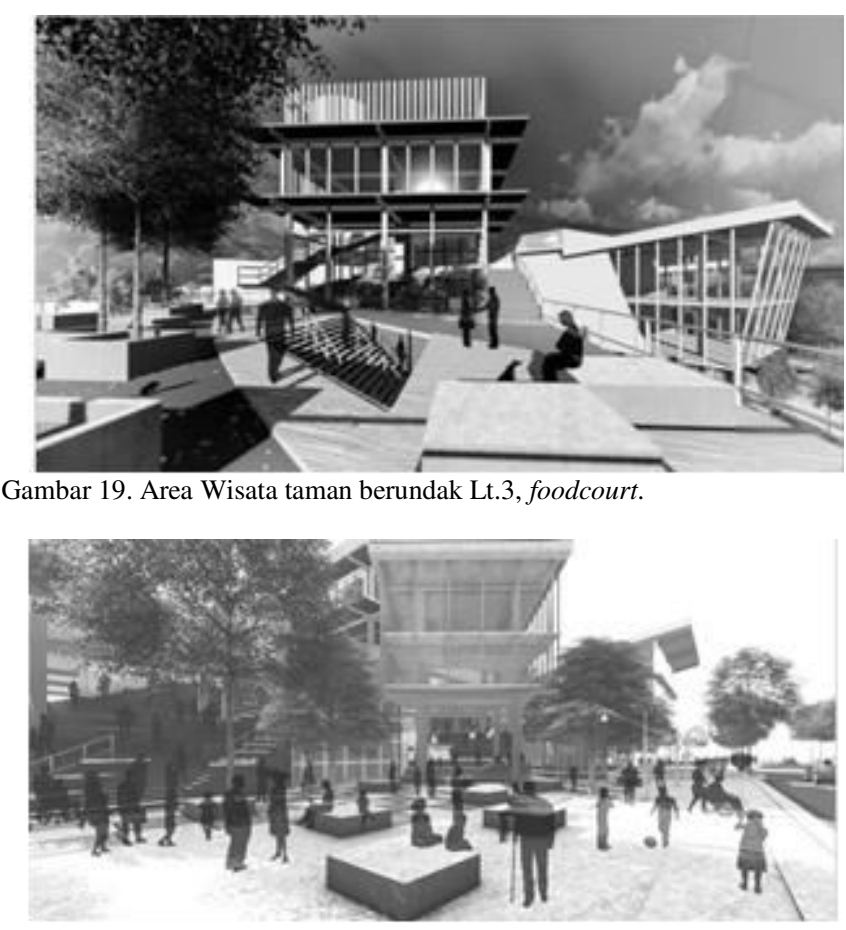

Gambar 20. Plaza penerima tamu.

karena keterbatasan lahan. Hadirnya ruang hijau untuk semua rumah dapat memberikan ruang baru bagi interaksi penghuni bersama (Gambar 12). Kedua, fasilitas tangga. Desain memperhatikan bahwa tidak harus setiap rumah memiliki tangga. Tangga merupakan alat transportasi khusus penghuni yang menghubungkan hunian dan toko, jadi selama tangga tersebut berada di area hunian yang tidak diakses secara bebas oleh pengunjung, tangga tersebut dajadikan publik (Gambar 13). Ketiga, fasilitas jemur baju. Dengan beberapa konsep penyekat untuk tetap membatasi kepemilikan area jemur antar penghuni, aktivitas jemur baju dapat dilakukan di ruang yang sama (Gambar 14). Terakhir, fasilitas ruang tamu hunian. Ruang tamu adalah bagian dari hunian yang presentase penggunaan sesuai fungsinya lebih rendah dari ruang - ruang lain di hunian. Tidak setiap hari penghuni akan memiliki tamu, ruang ini akan lebih rendah penggunaannya. Desain mencoba mengeluarkan ruang tamu tersebut sebagai area penerima tamu bersama. Saat tidak ada tamu ruang tersebut dapat menjadi tambahan area berkumpul bagi fungsi taman, wisata, foodcourt dan lainnya. Dengan begitu penggunaan area ini dapat digunakan secara lebih efisien (Gambar 11).

10. Konsep Taman

Taman yang dihadirkan pada desain adalah taman perbatasan. Taman yang menyatukan antara kota Surabaya dan kabupaten Gresik. Taman memiliki konsep 2 layer untuk memberikan kesamaan hak ruang terbuka untuk aktivitas perdagangan (layer 1) dan hunian (layer 2). Selain itu, hal tersebut bertujuan untuk menambah ruang baru bagi fasilitas wisata yang dibutuhkan. Vegetasi pada taman menggunakan beragam jenis berdasarkan preseden pada taman - taman di Surabaya lainnya (Gambar 15, 16 dan 17).

11. Konsep Wisata

Konsep pembagian fasilitas dan area wisata dikategorikan menjadi 3 kategori. Pertama, SI : Social Interaction, fasilitas 
untuk pengguna bertemu di area publik dan cenderung terbuka atau ternaungi. Kedua, BDS : Building Social, fasilitas rekreasi untuk publik yang terlindungi. Ketiga, BDT : Bulding Technical, fasilitas dalam bangunan yang tidak berhubungan langsung sebagai area wisata atau publik. Digunakan untuk keperluan teknis maupun aktivitas khusus.

Pembagian kategori tersebut digunakan untuk menentukan peletakan fasilitas tersebut pada desain (Gambar 18). Beberapa fasilitas yang paling menarik pengunjung diletakkan pada lantai atas (Gambar 19). Sedangkan, fasilitas lain diletakan pada lantai bawah untuk menerima aktivitas publik yang lebih banyak (Gambar 20). Tujuan peletakkan ini agar arah pengunjung dapat didistribusikan secara merata pada seluruh area.

\section{KESIMPULAN}

Kualitas suatu wilayah dapat ditingkatkan melalui fungsi yang ada di wilayah itu sendiri.. Strategi yang dihadirkan dengan melakukan re-desain fungsi hunian dan perdagangan pada lahan, lalu menambahkan fungsi taman dan wisata untuk meningkatkan kualitas ruangnya, dan menjadikan area tersebut sebagai generator finansial bagi masyarakat sekitar.

Kombinasi fungsi tersebut disederhanakan dengan memrogramkan semua fasilitas yang ada agar memberikan kualitas antar ruang yang baru, dan lansekap yang lebih baik. Selain itu, mampu meningkatkan kualitas sosial dan lingkungan masyarakat, dan mendukung meningkatnya kenyamanan suatu wilayah.

\section{DAFTAR PUSTAKA}

[1] Anonymous, "Wawancara Kompas dan Bu Risma Visi Misi Kota Surabaya 2016 - 2021." 2011.

[2] W. Shirly, "Kota Humanis (integrasi guna lahan dan transportasi di Wilayah Sub urban)." 2012.

[3] Badan Perencanaan dan Pembangunan Kota, "Wawancara Bidang Fisik Sarpras Badan Perencanaan dan Pembangunan Kota." Surabaya, 2017.

[4] C. Ali and T. Heat, "Urban Identities: Influences on SocioEnvironmental Values and Spatial Inter-Relations," in ASEAN Conference on Environment-Behaviour Studies, 2012, pp. 53-70.

[5] J. Kari, "Design Method." 2008. 